

\title{
É tempo de aquilombar: da tecnologia ancestral à produção cultural contemporânea
}

\author{
Stéfane Souto
}

1 Graduada no curso de comunicação social com habilitação em produção em comunicação e cultura pela Universidade Federal da Bahia (Ufba) e especialista em gestão cultural contemporânea pelos institutos Itaú Cultural e Singularidades. Atualmente cursa o mestrado em cultura e sociedade pelo Instituto de Humanidades, Artes e Ciências Professor Milton Santos (Ihac-Ufba), onde desenvolve pesquisa sobre experiências de aquilombamento do povo negro no campo das artes e da cultura, sob uma perspectiva insurgente e engajada da gestão da cultura. E-mail: stefanesouto@gmail.com. 


\section{RESUMO}

Neste ensaio, busco desenvolver uma reflexão acerca do aquilombamento em sua dimensão ancestral, social e cultural. Para tanto, recorro ao legado deixado pela pesquisadora Beatriz Nascimento sobre a historiografia da instituição quilombo no Brasil, com o objetivo de compreender suas apropriações e desdobramentos através do tempo até alcançar um conceito de aquilombamento que considere sua inscrição no presente e suas possibilidades de futuro. Com isso, procuro evidenciar como o ato de se aquilombar constitui uma tecnologia ancestral de organização social e cultural própria das populações negras que vem garantindo a atualização dos seus mecanismos de resistência e inspirando a apropriação estratégica dos instrumentos culturais para imaginar um devir negro.

Palavras-chave: Aquilombamento. Quilombo. Produção cultural. Tecnologia ancestral. Organização social.

\section{ABSTRACT}

In this paper, I intend to reflect about the aquilombamento in its ancestral, social, and cultural dimension. To this end, I turn to the legacy left by researcher Beatriz Nascimento on the historiography of the quilombo institution in Brazil, seeking to understand its appropriations and developments until reaching a concept of aquilombamento that considers its present inscription and future possibilities. With this, I try to show how the act of aquilombar constitutes an ancestral technology of social and cultural organization proper to Black populations, which has been guaranteeing the updating of their resistance mechanisms and inspiring the strategic appropriation of cultural instruments to imagine a Black becoming.

Keywords: Aquilombamento. Quilombo. Cultural production. Ancestral technology. Social organization. 


\section{A BENÇÃO, MINHA MAIS VELHA}

No que se refere aos debates e discussões que aquecem e oxigenam o pensamento negro na atualidade, aquilombamento é, sem dúvidas, uma palavra do nosso tempo. De diferentes formas e em diversos espaços, sejam estes físicos ou virtuais, a ideia de quilombo vem sendo evocada com cada vez mais frequência, sobretudo por jovens negros e negras interessados e interessadas em tecer novas redes de organização e colaboração frente às condições colocadas pela opressão racial. Nesse momento, é possível observar que a urgência desse enunciado emerge como resposta ao acirramento de forças que levam a uma situação-limite. Frente à crescente polarização ideológica e política, ao desmantelamento das instituições, aos retrocessos (in)constitucionais e ao agravamento da situação de vulnerabilidade da população negra nesse contexto genocida, é preciso aquilombar-se. Mas o que isso significa? Como e por que a memória do quilombo surge nesse momento e que perspectivas de presente e futuro ela traz para nós, aqueles e aquelas que a evocam? Pensar a atualização do conceito de quilombo através do tempo na história do Brasil é, na verdade, um empreendimento inaugurado pela pesquisadora sergipana Maria Beatriz Nascimento. A autora é responsável por realizar um estudo sensível e aprofundado sobre a 
experiência quilombola no Brasil, demonstrando o continuum cultural existente entre Brasil e África no período em que esse modelo de organização comunitária se instituiu no interior da colônia portuguesa. A pesquisa empreendida por Beatriz Nascimento desafia a historiografia oficial construída sobre os quilombos brasileiros, uma vez que ultrapassa o imaginário combativo atribuído à organização quilombola e evidencia seus aspectos sociais e culturais, chamando a atenção para os impactos e as influências que a experiência do quilombo causou, desde então, não só na vida das pessoas negras, mas da sociedade brasileira como um todo. Talvez por isso, por apresentar outra versão dos fatos e desafiar os regimes de verdade aqui estabelecidos, o trabalho de Beatriz Nascimento tenha sido negligenciado por tanto tempo, permanecendo ausente dos currículos escolares e universitários.

Não é à toa, porém, que a sua obra - produzida sobretudo entre as décadas de 1970 e 1980, até o início da década de 1990, quando é fatalmente interrompida pela sua morte trágica, vitimada pelo feminicídio - vem sendo retomada e difundida nos últimos anos, fornecendo à nossa geração de pesquisadores negros e negras verdadeiras oferendas despachadas nas rotas de fuga do aprendizado e do conhecimento, ou seja, insumos teóricos suficientes para alimentar Orí, abrindo perspectivas de reflexão e análise até então encobertos pelo epistemicídio praticado no sistema educacional brasileiro. Um nítido reflexo das ações afirmativas que promoveram o ingresso expressivo de pessoas negras nas universidades públicas brasileiras através das políticas de reserva de vagas e de permanência, pois, ao ocupar esse universo até então dominado pela intelectualidade branca, essa nova geração de pesquisadores negros e negras não se satisfaz apenas com o acesso e reivindica que seus saberes e referências sejam também representados, tensionando a hegemonia do conhecimento no ensino universitário.

Por esse motivo, aproveito as páginas iniciais deste texto para pedir a benção à minha mais velha, Maria Beatriz Nascimento - mulher, 
negra, intelectual e nordestina, como eu -, com a intenção de, uma vez atravessada por suas ideias, contar também com sua lucidez para refletir sobre o meu próprio tempo. Para isso, mantenho seu pensamento em vista durante todo esse texto e para além dele, principalmente quando a autora diz que:

O quilombo é um avanço, é produzir ou reproduzir um momento de paz. Quilombo é um guerreiro quando precisa ser um guerreiro. E também é o recuo quando a luta não é necessária. É uma sapiência, uma sabedoria. A continuidade de vida, o ato de criar um momento feliz, mesmo quando o inimigo é poderoso, e mesmo quando ele quer matar você. A resistência. Uma possibilidade nos dias de destruição. (NASCIMENTO, 2018, p. 7)

É com essa compreensão de quilombo - como uma possibilidade nos dias de destruição - que irei trabalhar para pensar o ato de se aquilombar como prática cultural que atravessa a trajetória da experiência negra no Brasil. Porém, para alcançar essa reflexão, considero necessário primeiramente compreender o significado do quilombo na experiência afrodiaspórica brasileira, para em seguida entender quais os usos e sentidos desse fenômeno hoje.

Beatriz Nascimento localiza o surgimento do kilombo enquanto instituição no continente africano do século XVII, identificando a formação social criada pelo povo bantu Imbangala, comunidade guerreira de homens nômades. Considerando a natureza polissêmica das línguas bantu, o termo kilombo assumia, nesse contexto, significados diversos, nomeando o rito de iniciação que assimilava guerreiros de etnias diversas ao grupo Imbangala, o espaço sagrado onde o ritual era realizado, o acampamento desses homens ou mesmo os próprios indivíduos ao se incorporarem à sociedade Imbangala. Ou seja, a palavra kilombo, de origem bantu, está ligada à própria prática guerreira deste povo e aos processos que lhe constituíam. Indo além, Nascimento observa que, considerando a inter-relação entre Brasil e Angola decorrente do tráfico negreiro, não é 
difícil estabelecer conexão entre a história da instituição kilombo na África, mais especificamente no território angolano, e a experiência quilombola brasileira (NASCIMENTO, 2018, p. 119). Esse pensamento é corroborado pelo pesquisador Kabengele Munanga, ao identificar que "Zumbi, líder do Quilombo dos Palmares, foi morto em 1695, quase no fim do século XVII. Coincidentemente, a formação da instituição kilombo no continente africano, especificamente na área cultural bantu, aconteceu também nos séculos XVI e XVII" (MUNANGA, 1996, p. 63). Segundo Munanga,

Pelo conteúdo, o quilombo brasileiro é, sem dúvida, uma cópia do quilombo africano reconstruído pelos escravizados para se opor a uma estrutura escravocrata, pela implantação de uma outra estrutura política na qual se encontraram todos os oprimidos. [...] Imitando o modelo africano, eles transformaram esses territórios em espécie de campos de iniciação à resistência, campos esses abertos a todos os oprimidos da sociedade (negros, índios e brancos), prefigurando um modelo de democracia plurirracial que o Brasil ainda está a buscar. (MUNANGA, 1996, p. 63)

No entanto, os conceitos atribuídos ao quilombo segundo a documentação oficial brasileira não alcançam tal nível de complexidade cultural, social e política, pois, embora o termo kilombo tenha assumido significações diversas no território angolano pré-colonial, no Brasil, em um primeiro momento, o termo "quilombo" foi capturado pelo regime escravocrata como estabelecimento de pessoas negras escravizadas fugidas, propagando uma compreensão preconceituosa e criminalista que, a despeito do que significava o quilombo para as pessoas negras nele imbricadas, descrevia a instituição quilombola como "toda a habitação de negros fugidos que passem de cinco, em parte desprovida, ainda que não tenham ranchos levantados nem se achem pilöes neles" (NASCIMENTO, 2018, p. 119). Ou seja, eram considerados quilombos qualquer espaço 
que abrigasse um agrupamento de pessoas negras escravizadas em fuga, não importando se estavam presentes sinais de organização comunitária ou não.

Em um segundo momento, atribui-se ao quilombo uma compreensão primitivista, que o define como uma necessidade de as pessoas africanas reconstituírem a experiência "tribal" supostamente vivida em África e, por esse motivo, fugirem, evitando inclusive a luta, ou seja, o enfrentamento direto à ordem escravocrata. Em qualquer uma dessas leituras, o simbolismo do quilombo para aqueles e aquelas que o fundaram e constituíram, pretos e pretas trazidos de África ou nascidos no Brasil, é desprezado em razão de uma narrativa colonial que reduzia e aprisionava a subjetividade das pessoas negras a uma espécie de sub-humanidade.

Somente no final do século XIX o conceito de quilombo começa a assumir no imaginário nacional, principalmente no que se refere à intelectualidade brasileira, características ideológicas de resistência e libertação. No início do século XX, através do movimento artístico modernista, ele se converte em símbolo da identidade nacional, sendo antropofagizado por um negrismo que absorve o negro enquanto recurso estético de um novo Brasil que se anuncia para o mundo moderno, mas que não se preocupa em remover esse mesmo negro da posição de exploração e subalternidade.

O trabalho de Beatriz Nascimento se contrapõe a esse percurso narrativo oficial na medida em que busca olhar para a história do quilombo não pela perspectiva do Estado brasileiro, mas através dos símbolos e significados que a vivência quilombola alimentou no imaginário negro em toda a experiência da diáspora. Ainda que a noção de quilombo tenha permanecido intrinsecamente ligada à ideia de fuga no imaginário nacional, Nascimento nos mostra, por exemplo, que a fuga nada tem a ver com uma posição resiliente de desistência, derrota ou covardia frente ao regime escravocrata, sendo na verdade um recuo estratégico para a sobrevivência e 
busca de melhores condições de existência e também de resistência. Novamente, uma possibilidade nos nossos dias de destruição.

Obviamente, inúmeras outras formas de resistência à dominação colonial foram empreendidas pelas pessoas negras em situação de escravidão, do nível individual ao coletivo, de suicídios a revoltas organizadas. No entanto, e considerando as condições de precariedade material em que essas pessoas se encontravam na maioria das vezes, bem como a iminência do castigo e da morte como consequência a qualquer expressão de revolta, a fuga pode ser compreendida como o método de reação que verdadeiramente poderia significar a criação de uma nova ordem autônoma e desviante à ordem colonial.

Porém, como sinaliza Nascimento, não se trata de uma fuga espontânea no sentido de anarquia e desorganização. A fuga é planejada como uma das etapas envolvidas na criação de outra possibilidade de vida, motivada pela necessidade de resistência, que se realiza quando negros engajados se insurgem contra a ordem oficial e se organizam para dela se libertar. O quilombo não pode, portanto, se reduzir à fuga, embora a compreenda de forma intrínseca (NASCIMENTO, 2018, p. 74). Isso porque, só quando são vencidas as etapas de insurgência silenciosa, organização interna, escolha do território e, posteriormente, de fuga em si, é que o quilombo é, de fato, fundado.

Nascimento chama de "a paz quilombola" o período em que o quilombo começa a organizar sua estrutura social interna, autônoma e articulada com o mundo externo (NASCIMENTO, 2018, p. 76). É graças a esse período que o quilombo se constitui enquanto momento histórico brasileiro de longa duração, como define nossa autora, capaz de coexistir ao longo de trezentos anos em plena dominação colonial europeia. Embora seja esse o momento quilombola menos narrado pela história oficial, não por coincidência, é nos períodos de paz, vividos nos intervalos entre um ataque e outro, uma repressão e outra, que as comunidades negras aquilombadas 
estabelecem suas regras sociais, seus modos de produção, seus mecanismos políticos, suas práticas culturais e suas táticas de guerra, observando-se as devidas diferenças de uma organização para outra. É o período em que o sentido de existência plena é verdadeiramente vivido e durante o qual as táticas de enfrentamento e resistência são estrategicamente pensadas.

É certo que, enquanto os conceitos atribuídos ao quilombo versam principalmente sobre o seu caráter de fuga e esconderijo de "negros fujōes" - como a população quilombola foi historicamente denominada - e a bibliografia oficial se detém predominantemente sobre seu caráter insurrecto e guerrilheiro, narrando especialmente os confrontos travados com as forças imperiais em suas ostensivas tentativas de aniquilamento e desmonte, pouquíssimo conhecimento é difundido, ainda nos dias de hoje, sobre os sistemas sociais fundados pelos quilombos. Nada de muito diferente do que podemos observar nos dias atuais, se fizermos um paralelo com a realidade vivida pelas favelas das grandes cidades brasileiras e o tempo dedicado nos telejornais a narrar os conflitos armados e operações policiais, em comparação ao pouco tempo dedicado a evidenciar as relações sociais, as potências culturais e as redes e lideranças comunitárias que ali se formam. E ainda assim, Lélia Gonzalez nos lembra que

sabemos o quanto os terreiros de candombe, de umbanda, de batuque, de xangô, etc., foram perseguidos pela polícia, a mando de autoridades políticas e religiosas. Isto sem falar nos blocos e escolas de samba. De qualquer modo, as 'mães' e a 'tias' souberam segurar a barra e seus filhos e sobrinhos, fazendo de seus terreiros (religiosos ou de samba) verdadeiros centros de resistência cultural. (GONZALEZ, 2018, p. 121)

Embora a narrativa historiográfica que hoje é hegemônica destaque a história do quilombo apenas como uma história de insurreição e luta, foi a sua estrutura social comunitária e organizada 
que inspirou os sistemas sociais alternativos fundados por pessoas negras nos séculos e décadas posteriores até o presente momento. A fuga, a organização interna e a luta constituem mecanismos de resistência que as populações negras ativam e atualizam continuamente, sempre que é preciso traçar estratégias desviantes ao sistema dominante. É nesse sentido que Nascimento reflete que,

embora o quilombo enquanto agrupamento passível de repressão pareça só existir enquanto houve o sistema produtivo da escravidão, ele não pode ter desaparecido enquanto organização em que vários grupos sociais estão comprometidos somente porque o regime escravocrata extingue-se. (NASCIMENTO, 2018, p. 74)

Ou seja, ainda que a versão historicamente difundida sobre a instituição quilombo como território destinado ao agrupamento de pessoas negras fugidas dentro do regime escravocrata já não exista nessa mesma estrutura, o fim da escravidão no Brasil não representou a emancipação da população negra em relação à dominação branca, nem mesmo a integração dessas pessoas à sociedade da época, fazendo do racismo antinegro uma profunda ferida social que se perpetua até hoje e que atravessa a vida social e as instituições contemporâneas em todos os níveis. Nesse contexto, nunca houve na trajetória da população negra na diáspora brasileira um momento em que articular estratégias de resistência, sobrevivência e existência não fosse uma necessidade básica. $\mathrm{O}$ ato de se aquilombar, então, atravessa o tempo não apenas como memória, mas como metodologia de organização social, capaz de se adaptar às diferentes contingências vivenciadas pela população negra ao longo da história. Nessa travessia, o que observamos é a passagem do quilombo enquanto instituição para o quilombo como tecnologia. A essa tecnologia chamamos de aquilombamento, ou seja, o ato ou efeito de se aquilombar em diferentes circunstâncias. 


\section{UMA TECNOLOGIA ANCESTRAL NEGRA}

Pensar no quilombo como uma tecnologia ancestral de organização social e cultural pode ser o caminho para compreender a sua manifestação enquanto tecnologia de produção cultural na atualidade. Para isso, é preciso ir além no que compreendemos enquanto tecnologia, pois, quando falamos dela, pensamos quase que automaticamente em artefatos tecnológicos, com designs futuristas e funções cada vez mais autônomas e digitais. Essa ideia de tecnologia parece ser antagônica à ideia de ancestralidade, uma vez que este é o lugar do passado, daquilo que precisa ser superado para haver o avanço em direção ao desenvolvimento e ao progresso. No entanto, para além dessa compreensão instrumentalista e tecnocrata, que vincula a ideia de tecnologia ao artefato tecnológico, pesquisas recentes têm buscado expandir a noção de tecnologia de forma a considerar os valores culturais a ela inerentes.

Em busca de uma definição para o conceito de tecnologia ancestral, encontrei o estudo promovido pelos autores Estéfano Veraszto, Dirceu da Silva, Nonato de Miranda e a autora Fernanda Simon (2009), que realizaram uma revisão bibliográfica histórica com o objetivo de encontrar uma definição atual para o termo tecnologia entre as diferentes concepções apresentadas pela literatura especializada. Tal estudo apresenta uma compreensão alternativa de tecnologia que permite relacionar demanda social, produção tecnológica, política e economia ao enfatizar o processo que conduz o desenvolvimento tecnológico e ao incorporar a ele os aspectos culturais e organizacionais, além dos aspectos técnicos. Segundo eles, a tecnologia é concebida em função de novas demandas e exigências sociais, sendo uma resposta, uma solução criada para resolver os problemas práticos de uma comunidade, o que não se aplica somente ao desenvolvimento de utensílios e ferramentas, mas também à capacidade de desenvolver tecnologias simbólicas, como a linguagem e a escrita. Ou seja, 
Na medida em que muda padrões, a tecnologia também cria novas rotas de desenvolvimento. Portanto, trabalhar com tecnologia é trabalhar com algo dinâmico. O que hoje é ponta, amanhã é obsoleto, exigindo novos procedimentos, conceitos e atitudes para inovar. A tecnologia faz parte do acervo cultural de um povo, por isso existe na forma de conhecimento acumulado, e por essa mesma razão está em contínua produção. A tecnologia em si constitui- se, portanto, como uma forma de conhecimento e todas as tecnologias são produtos de todas as formas de conhecimento humano produzidas ao longo da história. (VERASZTO; SILVA; MIRANDA; SIMON, 2009, p. 78)

A tecnologia pode então ser compreendida como um conjunto de saberes inerente ao desenvolvimento e à concepção dos instrumentos criados pela humanidade ao longo de sua história, com o intuito de satisfazer às necessidades individuais e coletivas próprias do seu tempo (VERASZTO; SILVA; MIRANDA; SIMON, 2009, p. 78). O conhecimento tecnológico é, portanto, a expertise de saber fazer e de saber como fazer, desenvolvendo soluções através de mecanismos e instrumentos que serão usados para solucionar problemas práticos da experiência humana.

Ao utilizarmos essa concepção alternativa de tecnologia para analisar diferentes formas de organização social, podemos pensar nas tecnologias ancestrais como aquelas tecnologias simbólicas que foram pensadas por antepassados e antepassadas com o objetivo de enfrentar de forma estratégica questões próprias do seu tempo; que foram transmitidas de geração para geração através dos séculos; e que continuam sendo aplicadas e readequadas às demandas da atualidade.

Nesse sentido, o aquilombamento se apresenta como uma tecnologia simbólica e ancestral, própria da organização das comunidades negras, pensada no contexto da subjugação social justificada pela diferença e separabilidade aplicadas a partir da raça, com o objetivo de criar possibilidades de existência alternativa às condições de 
opressão impostas no momento histórico e que compreende a fuga, a organização interna e o enfrentamento por meio da luta como mecanismos de resistência e sobrevivência.

Se no período imperialista-escravocrata, foi necessário adentrar a mata, abrir clareiras e levantar mocambos para abrigar aqueles e aquelas que procuravam rotas de fuga, hoje a urgência de se aquilombar se manifesta no miolo das grandes cidades, em meio ao cotidiano de negros e negras que, ainda enclausurados/as em uma ordem social pautada no racismo estrutural, criam zonas temporárias de aquilombamento - aquelas onde as pessoas vivem a experiência de se aquilombar - de diferentes formas e nas mais variadas áreas de atuação, seja na educação, na economia, no direito, na política institucional, na saúde, no ambiente virtual, nas artes ou no campo cultural, por exemplo. Se um dia o ato de aquilombar esteve ancorado em aspectos territoriais, hoje o aquilombamento assume uma performance fragmentada, constituindo-se enquanto espaços de segurança, sejam estes físicos ou simbólicos, imbricados no dia a dia das comunidades negras. Isto é, se um dia a fuga representou uma experiência de vida alternativa ao sistema vigente, hoje a fuga significa uma experiência paralela e simultânea à inevitável assimilação da ordem social neoliberal que regimenta as sociedades ocidentais contemporâneas.

Ou seja, na experiência brasileira da diáspora negra, a tecnologia ancestral do aquilombamento, em sua temporalidade, se adapta e se atualiza às condições de opressão encontradas de forma a garantir a manutenção e preservação das formas sociais e culturais das comunidades negras. Mudam-se, então, os mecanismos e os instrumentos, mas o que permanece do quilombo através do tempo é o seu significado - de acolhimento, fortalecimento e organização estratégica -, ou seja, a sua dimensão cultural. 


\section{AQUILOMBANDO 0 TERRITÓRIO CULTURAL}

Acionar o conceito de tecnologia a partir de seus aspectos simbólicos ajuda a pensar o aquilombamento enquanto organização social e cultural, uma tecnologia ancestral que se realiza no presente e que funda as bases de um futuro possível. Porém, para compreender a sua permanência no tempo, é preciso evidenciar a importância da dimensão cultural intrínseca ao ato de aquilombar.

A dimensão cultural se encontra nos significados, nas formas e expressões simbólicas que uma comunidade agrega a um fenômeno. Sem isso, uma organização social humana não difere em nada da organização social de uma colmeia de abelhas ou de um formigueiro, por exemplo, ficando reduzida apenas à forma de se organizar, sem necessariamente compreender o que tal organização representa para os envolvidos e as envolvidas. São os aspectos simbólicos que lhe são atribuídos que fazem do fenômeno em questão uma tecnologia de organização social e cultural, da mesma forma que são esses os aspectos que acabam por revelar outra narrativa sobre a experiência do quilombo, a narrativa elaborada e transmitida por aqueles e aquelas que criaram, fundaram e viveram o quilombo.

Desde a sua instituição em solo brasileiro, a tecnologia do aquilombamento está impregnada de valores culturais que influenciam diretamente a formação das identidades negras na diáspora brasileira e nos seus métodos de produção de cultura. Sobre os modos sociais e culturais quilombolas, Munanga descreve que:

Apesar de o quilombo ser um modelo bantu, creio eu que, ao unir africanos de outras áreas culturais e outros descontentes não-africanos, ele teria recebido influências diversas, daí seu caráter transcultural. Com efeito, a transculturação parece-me um dado fundamental da cultura afro-brasileira. A "pureza" das culturas nagô e bantu é uma preocupação de alguns pesquisadores e nada tem a ver com as práticas e estratégias dos que nos legaram a chamada cultura negra no Brasil. Com efeito, 
os escravizados africanos e seus descendentes nunca ficaram presos aos modelos ideológicos excludentes. [...] Visavam a formação de identidades abertas, produzidas pela comunicação incessante com o outro, e não de identidades fechadas, geradas por barricadas culturais que excluem o outro. (MUNANGA, 1996, p. 63)

Sem dúvidas, a transculturalidade apontada por Munanga como característica intrínseca ao modelo do quilombo é, também, uma característica fundante da própria produção cultural negra, pois, na contingência da diáspora, a identidade negra "a todo momento esteve empenhada em inventar e fundar seus próprios referenciais, sua ideia de pertencimento e até mesmo sua noção de origem e ancestralidade com o objetivo de garantir a continuidade de suas memórias e existências" (SOUTO, 2020, p. 139). Nessa busca, as elaborações tornam-se híbridas, conectando a diversidade de culturas e saberes trazidos de África à diversidade de culturas e saberes apresentadas pelos povos indígenas originários da terra, sofrendo influência direta dos modos de vida europeus reproduzidos no Brasil colônia.

O aquilombamento cumpre o seu papel na preservação dos modos culturais negros e mantém vivos os aspectos que expressam o significado dessa tecnologia ainda nos dias de hoje. Aquilombamento, em qualquer tempo, diz respeito à criação de zonas de segurança, de acolhimento, de fortalecimento. Espaço onde é possível experimentar a paz de ser e estar em comunidade, compartilhar vivências, obter suporte, costurar alianças, alavancar projetos, reconhecer e curar feridas, tecer estratégias, planejar levantes, trocar informações, instruir-se uns aos outros. Local onde é possível o recuo e é desejado o avanço. O ato de se aquilombar compreende a necessidade de traçar caminhos desviantes e desafia a organização social neoliberal que ordena a separação dos corpos e a individualização das coletividades, formando e renovando continuamente uma inteligência coletiva. 
É importante ter em vista que foi preciso formar quilombos. Nunca foi possível não criar quilombos, e se essa urgência ainda se apresenta hoje, quais são os mecanismos e instrumentos disponíveis para levantar os mocambos contemporâneos? O campo da produção cultural se destaca hoje como uma das principais vias pelas quais o aquilombamento se expressa e se realiza. Através da organização de encontros, diálogos, eventos, festas populares ou produtos artísticos, a produção cultural realizada por pessoas negras vem mobilizando imagens e sentidos que colocam o aquilombamento em pauta, convocando, das mais diferentes maneiras, o pensamento negro a convergir mais uma vez em direção a uma posição coletiva e estratégica. Ativar a tecnologia do aquilombamento a partir da cultura na atualidade é essencial porque:

o ato de criar sentidos de aquilombamento através de signos culturais produz novas lógicas de representação e, consequentemente, uma relação direta de pertencimento e de identificação é criada com o público envolvido. Ao criar novas políticas de representação, redistribui-se a lógica de poder, pois a categoria que tradicionalmente entendemos como público é deslocada para a posição de produtora de cultura uma vez que, neste modelo, a prática da gestão (e da produção) se aproxima muito mais de um desenho circular do que de uma estrutura vertical. (SOUTO, 2020, p. 143)

Nessa perspectiva, o que fica evidente é que somos todos/as criadores de cultura, pois, quando uma pessoa negra ocupa um espaço destinado ao seu acolhimento, é acionado o sentido de pertencimento. É quando entendemos que fazemos parte da existência daquele lugar e que ele está em nossa rota de existência. Eu, em um espaço como esse, me entendo como sujeito e produtora de conhecimento, integrante de uma comunidade mais ampla. É esse o poder que a cultura nos oferta: o direito de existir enquanto pessoas, pensando, criando e realizando (REGINA, 2020). 
Pensar o quilombo hoje na cultura é, para além de pensar um espaço de acolhimento e fortalecimento, projetar também a criação de futuros possíveis (REGINA, 2020). Isto é, ir além da resistência e sobrevivência em meio às contingências do racismo na experiência de vida de pessoas negras para construir imagens que possam abrir novas rotas de fuga em direção a uma vida plena.

\section{REFERÊNCIAS}

GONZALEZ, L. Primavera para rosas negras: Lélia Gonzalez em primeira pessoa. São Paulo: Diáspora Africana, 2018.

MUNANGA, K. Origem e histórico do quilombo na África. Revista USP, São Paulo, n. 28, p. 56-63, 1996.

NASCIMENTO, M. B. Quilombola e intelectual: possibilidade nos dias de destruição. São Paulo: Diáspora Africana, 2018.

REGINA, T. Quilombos urbanos surgem como polos culturais na disputa por um novo Brasil. Ecoa UOL, [s. l.], 15 out. 2020. Disponível em: https://bit.ly/31ZByAF. Acesso em: 2 mar. 2021.

SOUTO, S. Aquilombar-se: insurgências negras na gestão cultural contemporânea. Revista Metamorfose, Salvador, v. 4, n. 4, p. 133-144, 2020.

VERASZTO, E. V.; SILVA, D.; MIRANDA, N. A.; SIMON, F. O.

Tecnologia: buscando uma definição para o conceito. Prisma.com, Porto, n. 8, p. 19-46, 2009. 